\title{
Late presentation of sorafenib-associated rash: a case report
}

Thomas Sarkodie, Paul Ross

\begin{abstract}
Introduction: Sorafenib, an oral multitargeted tyrosine kinase inhibitor, is licensed for the treatment of hepatocellular carcinoma. Rash is one of the most common side effects of its use, generally appearing within days to a few weeks of commencing treatment. We report the first case of rash appearing nine months after starting treatment with sorafenib.
\end{abstract}

Case presentation: A 75-year-old Caucasian man initially presented with asymptomatic transient jaundice. He was diagnosed with Barcelona Clinic Liver Cancer stage B hepatocellular carcinoma after extensive investigation. He tolerated sorafenib $400 \mathrm{mg}$ twice a day before presenting nine months later with a rash, confirmed to be druginduced.

Conclusions: Sorafenib is a drug of choice in Barcelona Clinic Liver Cancer stage B hepatocellular carcinoma. It can cause protracted rash quite late into treatment. Successful management of the rash could contribute to achieving stable disease in hepatocellular carcinoma over a significant period of time.

\section{Introduction}

Hepatocellular carcinoma (HCC) is the fifth most common neoplasm in the world and the third most frequent cause of cancer death worldwide [1]. The incidence of HCC is 500,000 to one million cases per year.

HCC is closely associated with hepatic cirrhosis in the western world, being found in about $70 \%$ of all cases. Treatment of HCC is effective in improving survival only when diagnosed at an early stage of the disease.

Tumor staging at diagnosis is essential in deciding appropriate treatment. The most recognized staging systems for HCC currently include the (i) Okuda staging system, (ii) Cancer of the Liver Italian Program (CLIP) scoring system and the (iii) Barcelona Clinic Liver Cancer (BCLC) staging (Tables 1 and 2) [2].

Using the BCLC staging stage A can be managed with radical therapies, such as resection, transplantation or percutaneous treatments. Stages B and C are managed with new agents in clinical trials or palliative care. Transarterial chemoembolization (TACE) is beneficial but is limited by patient suitability and maximum dose

\footnotetext{
* Correspondence: paul.ross@gstt.nhs.uk

* Correspondence: paul.ross@gstt.nhs.uk ISE5 9RT, UK
}

of chemotherapy agent used [3,4]. Stage D is for symptomatic treatment [5].

Sorafenib is an oral multitargeted tyrosine kinase inhibitor. It inhibits the receptor tyrosine receptors (RTKs), VEGFR 1-3 (vascular endothelial growth factor receptor), FLT-3 (fms-like tyrosine kinase receptor-3), PDGFR (platelet-derived growth factor receptor) and the non-receptor serine threonine kinases BRAF (B-Raf proto-oncogene serine/threonine-protein kinase) and (C-Raf proto-oncogene serine/threonine-protein kinase) CRAF. The BRAF and CRAF kinases are members of the RAF/(mitogen-activated protein kinase) MEK/(extracellular-signal-regulated kinases) ERK signaling cascade, which is involved in the survival and proliferation of tumor cells and is a therapeutic target in cancer [3-16].

Phase I trials of sorafenib demonstrated, in addition to safety, promising efficacy in HCC. It was well tolerated; most adverse events were mild to moderate in severity, with most reported side effects at any grade being fatigue (40\%), anorexia (35\%), diarrhea (34\%), rash/desquamation (27\%) and hand-foot skin reaction (25\%) [4,6,11].

Phase II trials evaluated efficacy and pharmacokinetics of sorafenib in HCC and demonstrated anti-tumor activity in HCC. In one trial of 137 patients, $2.2 \%$ of patients achieved a partial response and $33.6 \%$ had stable disease 
Table 1 The BCLC staging

\begin{tabular}{lllll}
\hline & \multicolumn{1}{l}{ Tumor Status } & Okuda Stage & Liver function \\
\hline BCLC Stage & PS & Tumor Stage & & No portal HT, normal bilirubin \\
\hline Stage A: early & 0 & Single, $<5 \mathrm{~cm}$ & I & Portal HT, normal bilirubin \\
\hline A1 & 0 & Single, $<5 \mathrm{~cm}$ & I & Portal HT, normal bilirubin \\
\hline A3 & 0 & Single, $<5 \mathrm{~cm}$ & I-II & Child-Pugh A-B \\
\hline A4 & 0 & 3 tumors, $<3 \mathrm{~cm}$ & & Child-Pugh A-B \\
\hline Stage B & & & I-I & Child-Pugh A-B \\
\hline Intermediate HCC & 0 & Large multinodular & I-II & Child-Pugh C \\
\hline Stage C: advanced & $1-2$ & Vascular invasion/extrahepatic spread & III &
\end{tabular}

over 16 weeks [7]. A subsequent multi-center phase III, double blind, placebo-controlled trial (SHARP trial) involving 602 patients with advanced HCC was conducted. The median survival was 10.7 months in the sorafenib group and 7.9 months in the placebo group $(P \leq 0.001)[15]$.

\section{Case presentation}

A 75-year-old Caucasian man was referred for consideration of systemic therapy after being diagnosed with HCC. Prior to this diagnosis, he had been fit and well. Past medical history was notable for type 2 diabetes mellitus diagnosed a year earlier, for which he took metformin. He initially presented jaundiced, which cleared spontaneously. Endoscopic retrograde cholangiopancreatogram (ECRP) was normal. Computed tomography (CT) scan (Figure 1A-C) demonstrated three large liver lesions, with the largest measuring under $5 \mathrm{~cm}$ in diameter, biopsy of which confirmed HCC.

$\mathrm{He}$ was well with performance status (PS) 0 , and a Child-Pugh score A, AFP (alpha-fetoprotein) $604 \mathrm{ku}-\mathrm{L}$. His BCLC staging was B (Intermediate). A study of sorafenib versus placebo was discussed with our patient and he was entered into the trial in September 2005. He was started on a trial medication at a dose of $400 \mathrm{mg}$ twice

Table 2 Okuda Staging System

\begin{tabular}{|c|c|c|c|}
\hline & & POINTS & \\
\hline & & 0 & 1 \\
\hline Tumor size & & $<50 \%$ liver & $>50 \%$ liver \\
\hline Ascites & & No & Yes \\
\hline Albumin $(\mathrm{g} / \mathrm{dL})$ & & $\geq 3$ & $<3$ \\
\hline Bilirubin (mg/dL) & & $<3$ & $\geq 3$ \\
\hline Okuda Stage & Points & & \\
\hline I & 0 & & \\
\hline$\|$ & $1-2$ & & \\
\hline III & $3-4$ & & \\
\hline
\end{tabular}

a day. The initial side effect experienced was grade I diarrhea managed with loperamide. CT scans a month into treatment demonstrated stable disease. Our patient was reviewed monthly. He remained well with stable disease. Nine months after commencing therapy he presented with a rash. This was initially a dry scaly, itchy rash, showing signs of early lichenification, mainly over the lower half of the abdomen (Figure 2). It gradually spread from the trunk to the arms within six weeks, and became pustular. Topical emollients were commenced with onset of the rash but their effect remained moderate after four months. At this point the rash flared up with some multiple ulcerations over the trunk and arms (Figure 3).

He was reviewed by a dermatologist and a working diagnosis of eczematous drug reaction was made. Biopsies were taken and the histology was reported as being in keeping with a drug reaction (Figure 4). Our patient was prescribed Fucibet cream (containing betamethasone $0.1 \%$, fucidic acid $2 \%$ ) to be applied twice daily for a week. The rash improved on subsequent reviews.

Fourteen months after commencing treatment (November 2006) our patient presented with a further rash of common toxicity criteria (CTC) grade 2 over his trunk and limbs. Study medication was stopped at that point. Four weeks later the rash had resolved so the trial medication was recommenced at a reduced dose of 400 mg daily. Our patient remained stable on monthly reviews. Four months later he developed a similar rash as previously; pruritic, mainly on the trunk, but worse on the back. Dermovate (clobetasol propionate 0.05\%), diprobase creams and Piriton (chlorphenamine) provided little relief so the trial drug was suspended. Within two months the rash resolved but our patient was not recommenced on trial medication. In spite of that, he again presented a new rash two months later (four months after stopping trial medication). A dermatologist suspected nodular prurigo. Biopsies were taken of the new rash. Histological findings were consistent 

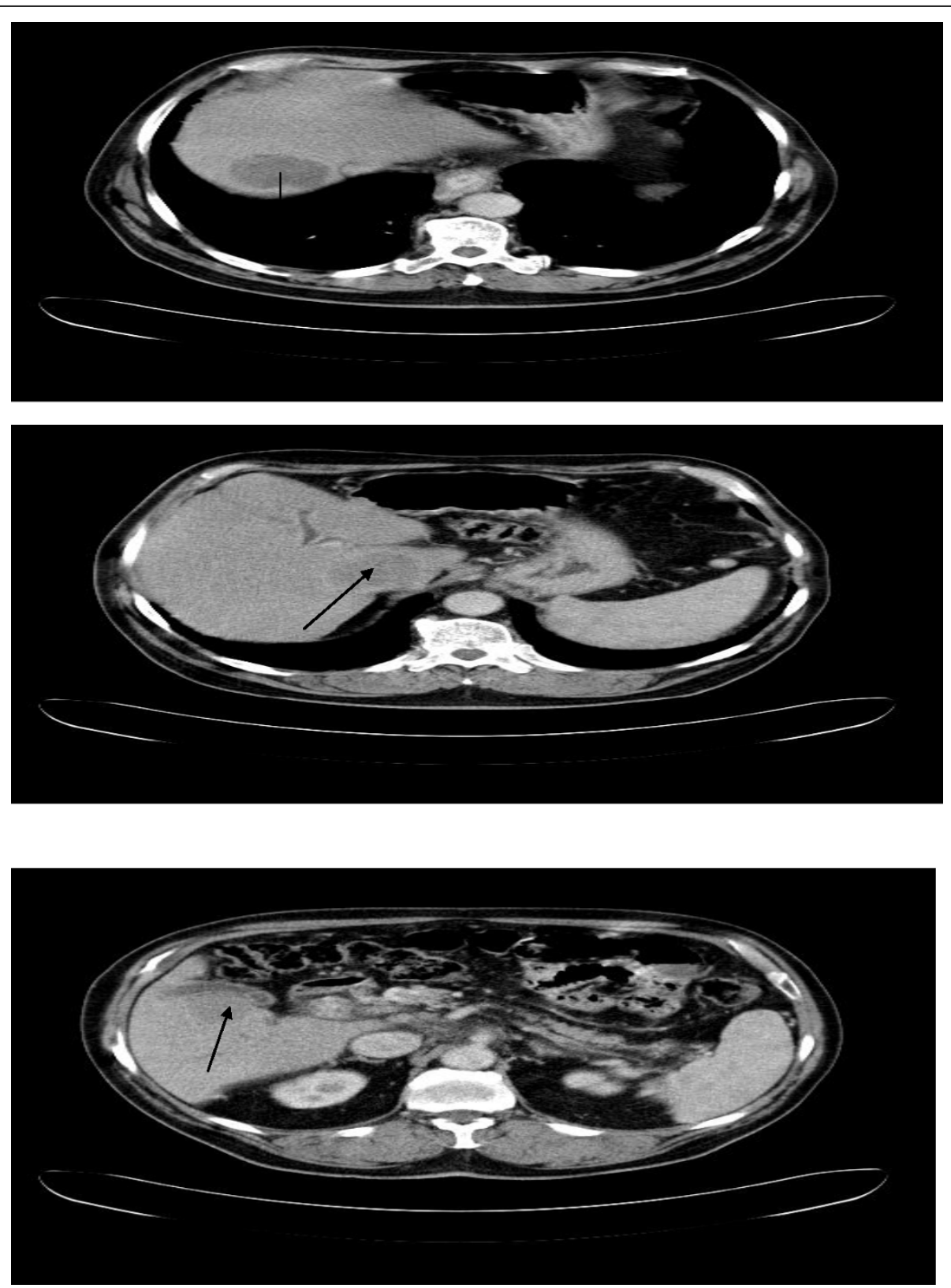

Figure 1 (A-C) CT scans (May 2005): HCC lesions in segment 7, caudate lobe, segment 5 of liver, respectively.

with nodular prurigo. This was managed with $1 \%$ menthol in aqueous cream and 1:4 betnovate ointments and the rash improved to CTC grade 1.

On the $2^{\text {nd }}$ August 2007 our patient agreed to resume treatment with sorafenib at a dose of $400 \mathrm{mg}$ on alternate days. The rash continued to improve and completely resolved by $30^{\text {th }}$ June 2008 (Figure 5). His latest CT scans at that time (Figure 6A-C) continued to show stable disease, almost three years after commencing treatment.

\section{Discussion}

Sorafenib (Nexavar, Bayer) is a molecular inhibitor of several tyrosine kinases. It targets the Raf/Mek/Erk pathway [3-16]. Its efficacy has been demonstrated in clinical trials $[4,6,7,11,16]$. Dermatological side effects including rash/desquamation (27\%), hand-foot skin reaction (HFSR, 27\%), pruritus (18\%) and dry skin (10\%) are well documented. Other side effects include fatigue (40\%), anorexia (35\%), diarrhea (40\%) hypertension and elevated amylase. 


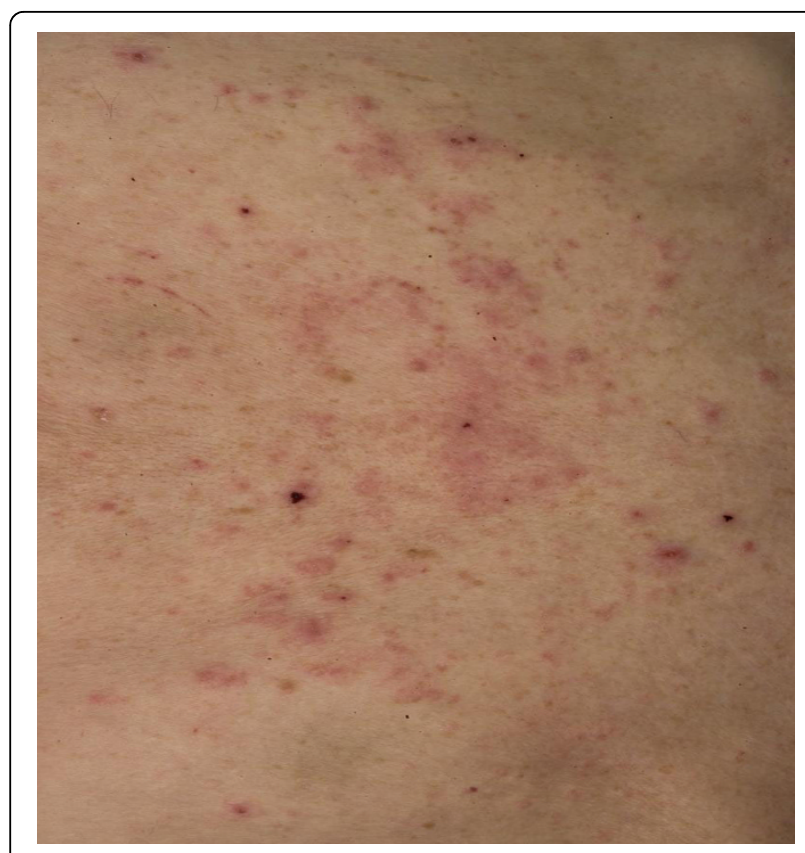

Figure 2 Drug reaction: rash on trunk.

The skin rash usually appears within a few weeks of commencing sorafenib $[8-11,17]$. The mechanism of the rash is poorly understood. There appears to be a relationship between the eccrine activity of the skin, resulting in higher drug concentration in the areas of the rash or desquamation [8]. Inhibition of HER-1/EGFR in the skin is also thought to play a role in the development of

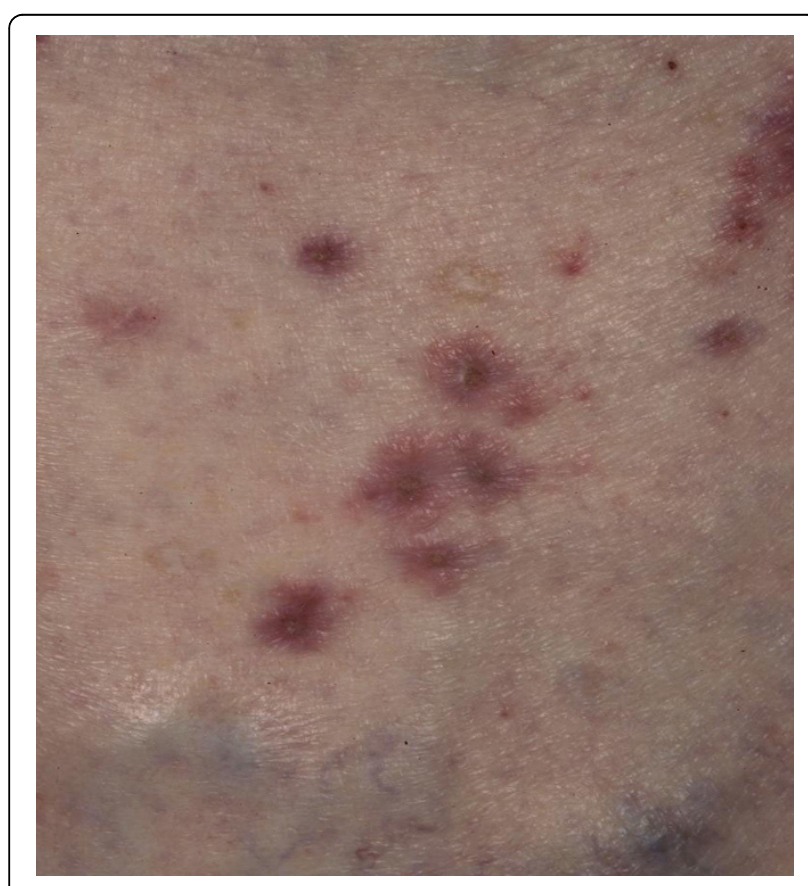

Figure 3 Drug reaction: rash on trunk.

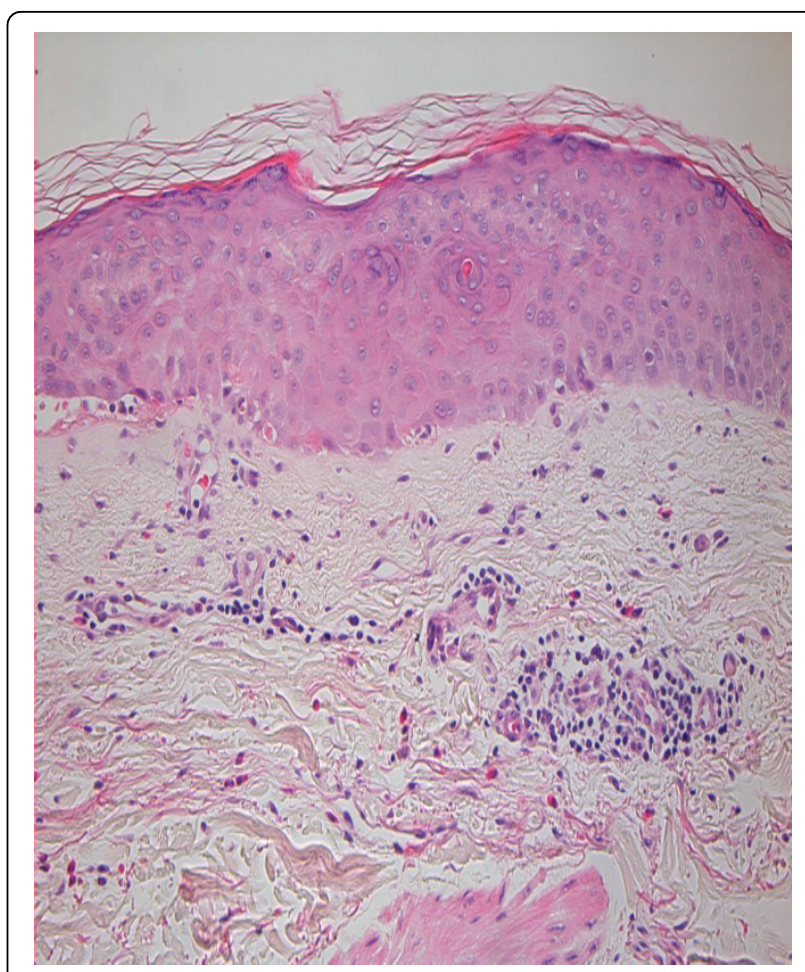

Figure $\mathbf{4}$ Histology of skin rash: drug reaction.

the rash [10]. Some studies found a relationship between the Child-Pugh score prior to commencement of medication and the severity of the adverse drug reaction [4].

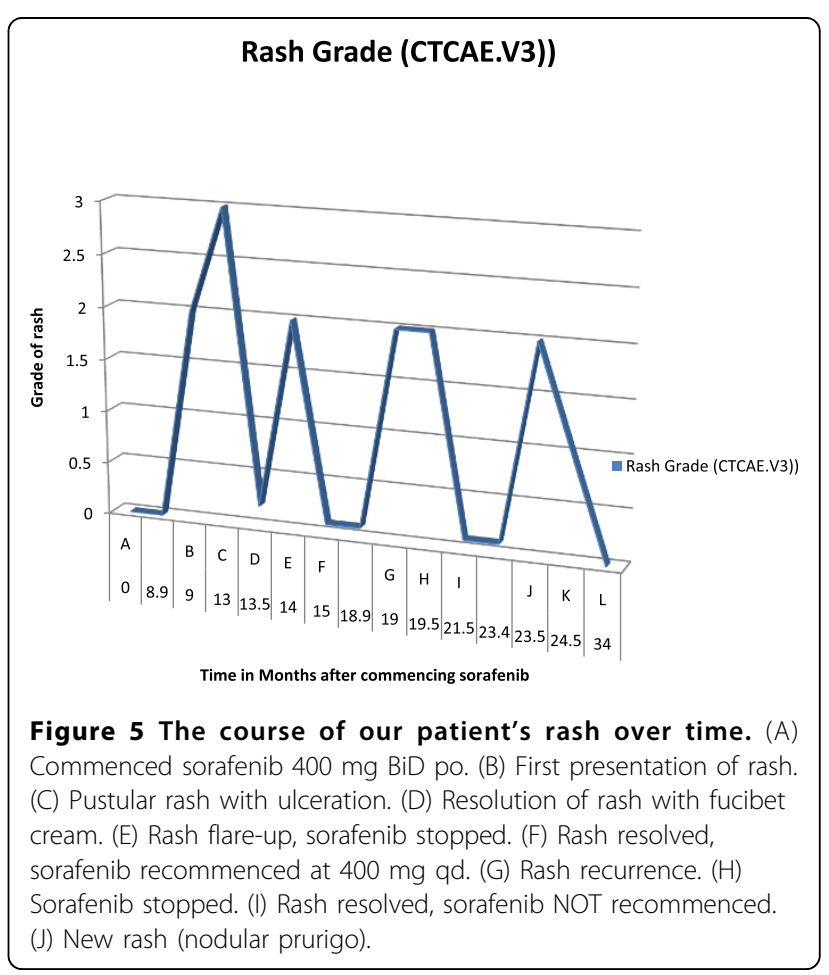



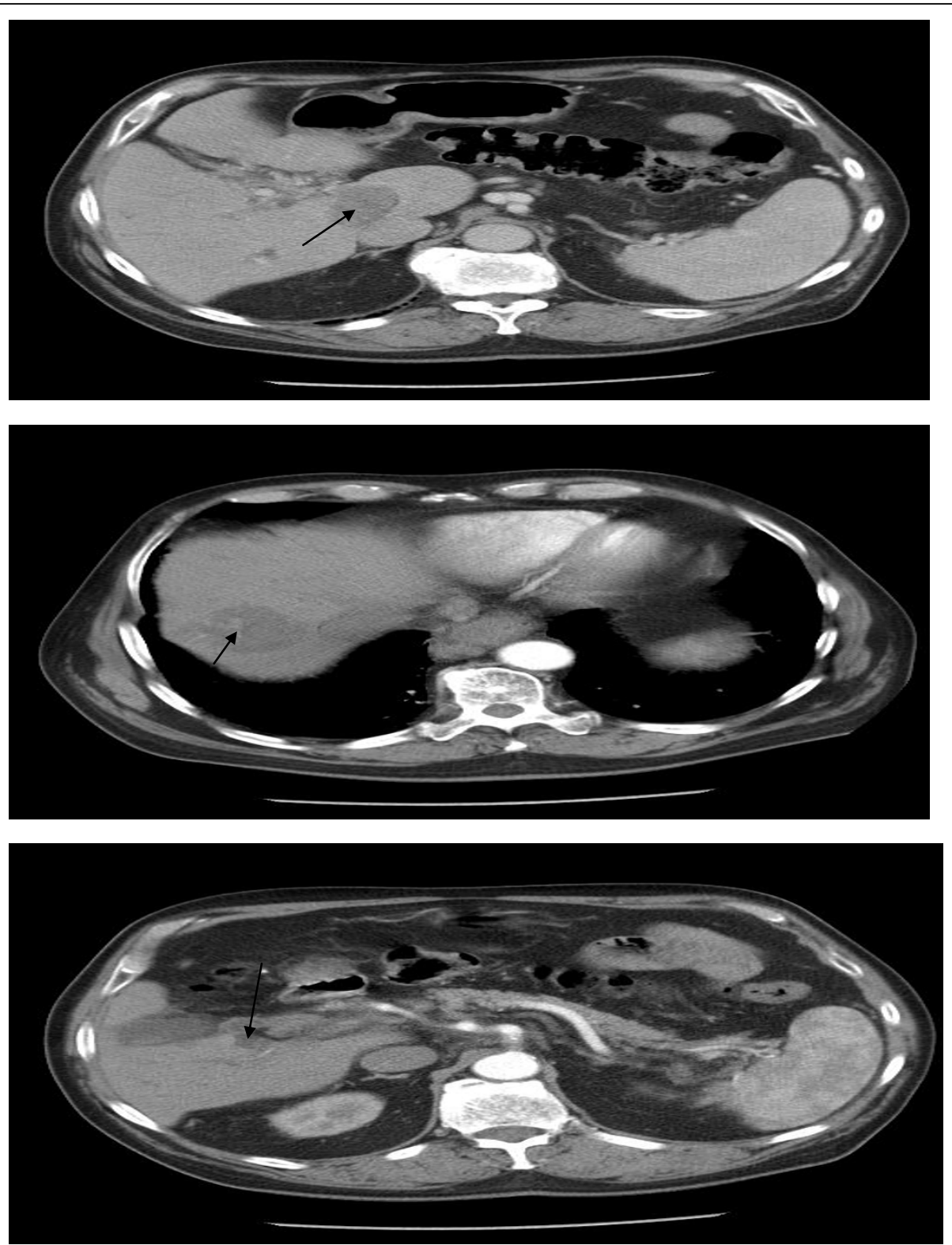

Figure 6 (A-C) CT scans (January 2008): HCC lesions in caudate lobe, segment 7 and segment 5 of liver, respectively

The late presentation of the rash in our patient appears to be the first reported of its kind in the literature to date. It first appeared nine months into treatment; it was mild to moderate in severity but was protracted and recurring. Management included moisturizing creams and topical steroids, the latter being of limited use [10]. Further improvements in our understanding of the pathogenesis underlying the side effects are needed in the management of these patients.

Unanswered questions regarding the protracted nature of the rash in our patient include whether the relatively long period the drug was tolerated prior to onset of the rash, might have contributed to its persistence four months after stopping the drug. Nodular prurigo, which could arise as a result of long-term scratching of the skin to any itchy stimulus, was confirmed in our patient by the second biopsy (Figure 7) as a consequence of the persistence of the original itchy rash. Reintroduction of the drug at a reduced dose after resolution of the rash did not precipitate recurrence. Our patient remained stable at this dose of medication by July 2008 .

\section{Conclusions}

Sorafenib, a multitargeted tyrosine kinase inhibitor, is a drug of choice in patients with BCLC stage B HCC. Skin rash is a common adverse drug reaction, occurring 


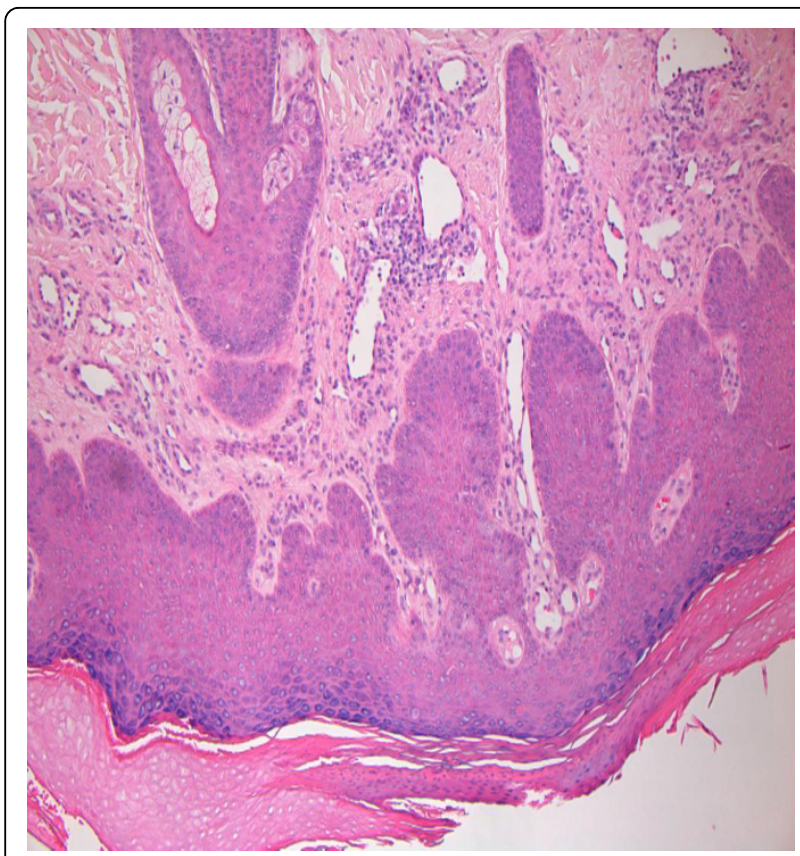

Figure 7 Histology of skin rash: nodular prurigo

within weeks of commencement of the drug. It is, however, important to note that the rash can present quite late into treatment. Prompt recognition and management of the rash remains vital to patients' outcome.

\section{Consent}

Written informed consent was obtained from the patient for publication of this case report and any accompanying images. A copy of the written consent is available for review by the Editor-in-Chief of this journal.

\section{Authors' contributions}

TS reviewed the case history and all data, wrote the manuscript. PS reviewed manuscript at all stages. All authors read and approved the final manuscript

\section{Competing interests}

The authors declare that they have no competing interests.

Received: 8 December 2009 Accepted: 25 October 2010

Published: 25 October 2010

\section{References}

1. Grieco A, Pompili M, Cominiti G, Miele L, Covino M, Alfei B, Rapacchini GL, Gasbarrini G: Prognostic factors for survival in patients with earlyintermediate hepatocellular carcinoma undergoing non-surgical therapy. Gut 2005, 54:411-418.

2. Levy I, Sherman M: Staging of HCC: assessment of CLIP, Okuda, ChildPugh Staging system in a cohort of 257 patients in Toronto. Gut 2003, 50(6):881-885.

3. Lee HS, Kim KM, Yoon JH, Lee TR, Suh KS, Lee KU, Chung JW, Park JH, Kim CY: Therapeutic efficacy of Transcatheter arterial chemoembolisation as compared with hepatic resection in HCC patients with compensated liver function in HBV-endemic area: a prospective cohort study. I Clin Oncol 2002, 20(22):4459-4465.
4. Furuse J, Ishii H, Nakachi K, Suzuki E, Shimizu S, Nakajima K: Phase I study of sorafenib in Japanese patients with hepatocellular carcinoma. Cancer Sci 2008, 99(1):159-165.

5. Llovet JM, Bru C, Bruix J: Prognosis of hepatocellular carcinoma: the BCLC staging classification. Semin Liver Dis 1999, 19(3):329-338.

6. Strumberg D, Clark JW, Awada A, Moore MJ, Richly H, Hendlisz A, Hirte HW, Eder JP, Lenz HJ, Schwartz B: Safety, pharmacokinetics and preliminary antitumour activity of sorafenib: a review of four phase I trials in patients with advanced refractory solid tumours. The Oncologist 2007, 12(4):426-437.

7. Abou-Alfa GK, Schwartz L, Ricci S, Amadori D, Santoro A, Figer A, De Greve J, Douillard JY, Lathia C, Schwartz B, Taylor I, Moscovici M, Saltz LB: Phase II study of sorafenib in patients with advanced hepatocellular carcinoma. J Clin Oncol 2006, 24(26):4293-4300.

8. Lai SE, Kuzel T, Lacouture ME: Hand-Foot and Stump Syndrome to sorafenib. J Clin Oncol 2007, 25(3):341-343.

9. Akaza H, Tsukamoto T, Murai M, Nakajima K, Naito S: Phase II study to investigate the efficacy, safety and pharmacokinetics of sorafenib in Japanese patients with advanced renal cell carcinoma. Jpn J Clin Oncol 2007, 37(10):755-762.

10. Porta C, Paglino C, Imarisio I, Bonomi L: Uncovering Pandora's vase: the growing problem of new toxicities from novel anticancer agents. The case of sorafenib and sunitinib. Clin Exp Med 2007, 7(4):127-134.

11. Minami H, Kawada K, Ebi H, Kitagawa K, Kim Yl, Araki K, Mukai H, Tahara M, Nakajima $\mathrm{H}$, Nakajima K: Phase I and pharmacokinetic study of sorafenib, an oral multikinase inhibitor, in Japanese patients with advanced refractory solid tumours. Cancer Sci 2008, 99(7):1492-1498.

12. Strumberg $D$, Richly $H$, Hilger RA, Schleucher $N$, Korfee $S$, Tewes $M$, Faghih M, Brendel E, Voliotis D, Haase CG, Schwartz B, Awada A, Voigtmann $R$, Schleulen ME, Seeber S: Phase I clinical and pharmacokinetic study of the novel raf kinase and vascular endothelial growth factor receptor inhibitor BY43-9006 in patients with advanced refractory solid tumors. J Clin Oncol 2005, 23(5):965-972.

13. Dahut WL, Scripture C, Posadas E, Jain L, Gulley JL, Arlen PM, Wright JJ, Yu Y, Cao L, Steinberg SM, Aragon-Ching JB, Venitz J, Jones E, Chen CC, Figg WD: A phase II clinical trial of sorafenib in androgen-independent prostate cancer. Clin Cancer Res 2008, 14(1):209-214.

14. Motzer RJ, Bukowski RM: Targeted therapy for metastatic renal cell carcinoma. J Clin Oncol 2006, 24(35):5601-5608.

15. Adjei AA, Hidalgo M: Intracellular signal transduction pathway proteins as targets for cancer therapy. J Clin Oncol 2005, 23(23):5386-5403.

16. Llovet JM, Ricci S, Mazzaferro V, Hilgard P, Gane E, Blanc JF, de Oliviera AC, Santoro A, Raoul JL, Forner A, Schwartz M, Porta C, Zuezem S, Bolondi L, Greten TF, Galle PR, Seitz JF, Borbath I, Haeussinger D, Giannaris T, Shan M, Moscovici M, Voliotis D, Bruix J, SHARP Investigators Study Group: Sorafenib in advanced hepatocellular carcinoma. N Engl J Med 2008, 359(4):378-390.

17. Procopio G, Verzoni E, Gevorgyan A, Mancin m, Pusceddu S, catena L, Platannia M, Guadalupi V, Martinetti A, Bajetta E: Safety and activity of sorafenib in different histotypes of advanced renal cell carcinoma. Oncology 2007, 73(3-4):204-209.

doi:10.1186/1752-1947-4-338

Cite this article as: Sarkodie and Ross: Late presentation of sorafenibassociated rash: a case report. Journal of Medical Case Reports 2010 4:338.

\section{Submit your next manuscript to BioMed Central and take full advantage of:}

- Convenient online submission

- Thorough peer review

- No space constraints or color figure charges

- Immediate publication on acceptance

- Inclusion in PubMed, CAS, Scopus and Google Scholar

- Research which is freely available for redistribution 